\title{
Nativism in Cognitive Science
}

\author{
RICHARD SAMUELS
}

\begin{abstract}
Though nativist hypotheses have played a pivotal role in the development of cognitive science, it remains exceedingly obscure how they-and the debates in which they figure- ought to be understood. The central aim of this paper is to provide an account which addresses this concern and in so doing: a) makes sense of the roles that nativist theorizing plays in cognitive science and, moreover, b), explains why it really matters to the contemporary study of cognition. I conclude by outlining a range of further implications of this account for current debate in cognitive science.
\end{abstract}

\section{Introduction}

Since the inception of cognitive science, disputes over nativism have played a pivotal role in the development of the discipline, and largely under the influence of Chomsky's work in linguistics, innateness hypotheses have become an important theoretical option that have been invoked in order to explain a wide range of cognitive phenomena, including our grammatical competence (Pinker, 1994) our ability to reason about the behavior of physical objects (Carey and Spelke, 1994) and our folk psychological capacities (Leslie, 1994). But in spite of their prominence, it remains exceedingly obscure how these hypotheses - and the debates in which they figure-ought to be understood. Moreover, the need to understand such nativist claims has become increasingly pressing in recent years. One reason is that the emergence of novel experimental techniques - especially in developmental neuroscience-has made the task of determining what should count as evidence for or against innateness hypotheses an increasingly difficult one. A second, and perhaps even more important reason, is that a number of prominent theorists-particularly developmental systems theorists - have mounted a serious challenge to the coherence

Earlier versions of this paper were presented at London University, Temple University, Washington University, the University of Sheffield and the ISHPPSB conference held in Oaxaca, Mexico. I am grateful for the many helpful suggestions that were offered on these occasions. Special thanks are due to Andre Ariew, Peter Carruthers, Andy Clark, Steve Downes, Peter Godfrey-Smith, Paul Griffiths, Stephen Gross, Dominic Murphy, David Owens, David Papineau, Sarah Patterson, Jessie Prinz, Jenny Saul, Gabriel Segal and Scott Sturgeon. I would also like to thank Mike Bishop, Gene Buckley, Fiona Cowie, Tim Crane, Steve Downes, Gary Hatfield, Ed Kako, Joel Pust, Tom Ricketts, Jonathan Sutton, Stephen Stich and an anonymous referee at Mind \& Language for valuable comments on earlier drafts of this paper.

Address for correspondence: Department of Philosophy, King's College London, Strand, London, WC2R 2LS, UK.

Email: richard.samuels@kcl.ac.uk 
and significance of nativism by arguing that the notion of innateness is at best unnecessary and at worst a deeply confused notion whose effect on the study of cognitive development has been profoundly detrimental (Oyama, 1985; Griffiths and Gray, 1992; Griffiths, 1997). ${ }^{1}$

The above concerns provide cognitive scientists who continue to engage in debate over nativism with a strong motive to clarify their enterprise and to show that it is important to the study of human cognition. This is the task that I pursue in the present paper. Specifically, there are two problems that I aim to address. The first-which I call the problem of general nativism-requires us to answer the following question: In what does the general distinction between nativism and non-nativism in cognitive science consist? The second problemthe problem of special nativism-requires us to explain how claims about the innateness of specific (kinds of) cognitive structure, such as concepts, beliefs, modules and learning mechanisms, ought to be understood. As I construe it, this is equivalent to explaining what it is to be a nativist with respect to some specific (kind of) cognitive structure. In addressing these questions, I develop an account of nativism, which, for want of a better name, I call primitivism. According to this account-which is similar to a proposal developed by Fiona Cowie-innate cognitive structures are ones that are not acquired by any psychological process or mechanism. I argue that a suitable elaboration of this view has the notable virtue of explaining the central roles that the notion of innateness - and debate over nativism - play in the inferential and explanatory practices of cognitive science and, moreover, shows why they really matter to the contemporary study of cognition. ${ }^{2}$

Before providing such an account, however, I first need to say something about what roles the notion of innateness plays in cognitive science-to lay down some constraints that our theory ought to satisfy. I address this task in section 1 . Then, in section 2, I invoke these constraints in arguing against a cluster of highly influential approaches to understanding innateness; what I call invariance accounts. Moreover, I provide a diagnosis of why such accounts fail

Moreover, even if one doesn't endorse such an extreme view, one might reasonably wonder why, given our increasing abilities to produce more detailed models of psychological development, such a venerable topic as innateness should be of anything more than marginal interest to cognitive science.

2 It is perhaps worth stressing that primitivism is not intended to be a piece of ordinary language conceptual analysis-i.e. an analysis of our 'folk' notion of innateness. Though such an analysis might be useful for some purposes, I have two reasons for not pursuing it here. First, I strongly suspect that our ordinary uses of 'innate' and its cognates are at best various and at worst confused. (See Griffiths, 1997, pp. 55-64, for arguments in support of this claim.) Second, there is clearly no a priori reason to suppose that an analysis of a folk notion of innateness - even if it could be provided — would shed much light on nativism in contemporary cognitive science. Indeed, this is no more plausible than the claim that an analysis of our folk notion of force would shed light on the contemporary physicist's notion of force. To the extent, then, that we are primarily interested in understanding nativism within cognitive science, analyzing a folk concept would not appear to be an attractive strategy.

(C) Blackwell Publishers Ltd. 2002 
to satisfy these constraints and suggest that the diagnosis motivates an alternative approach to understanding nativism. With this in mind, in section 3 I sketch the primitivist account and, in section 4, I show that it accommodates all our constraints on an adequate account of innateness and, to that extent, constitutes a highly attractive proposal. But despite its notable virtues, there is a major problem with the initial formulation of the primitivist account, namely that it incorrectly categorizes psychological structures that are acquired via accidental, nonpsychological processes, such as brain lesioning, as innate. In section 5, I discuss this problem and explore a number of ways in which it might be resolved. Finally, in section 6, I argue that the primitivist account has a number of further implications for how we should think about nativism in cognitive science. Not only does it suggest that a range of highly influential anti-nativist arguments from experimental neuroscience are simply irrelevant to disputes over nativism, but it also explains some of the most striking features of the contemporary debate. In particular, it explains why debates over nativism are so hard resolve and why they frequently devolve into disputes over the nature of scientific psychological explanation - specifically, over the framework within which scientific, psychological theories ought to be couched. If the primitivist account is correct, the debate over nativism in cognitive science is not merely a contemporary recasting of the age-old nature/nurture debate. At its heart, it is a dispute over the very nature of scientific psychological theorizing.

\section{Some Constraints on an Account of Nativism in Cognitive Science}

There are a number of constraints or desiderata that a satisfactory account of nativism in cognitive science should (at least ideally) satisfy. Some of these constraints are more important than others. Moreover, virtually all of them are defeasible and most of them ceterus paribus. In this section, I describe four different kinds of desiderata-what I call conceptual constraints, argument constraints, logical geography constraints and significance constraints. I'll indicate, where appropriate, the relative importance of these desiderata.

\subsection{Conceptual Constraints}

One central kind of constraint on a satisfactory account of nativism in cognitive science is that it should preserve widely accepted conceptual truths that constrain the notion of innateness as cognitive scientists deploy it. ${ }^{3}$ If such a condition is not satisfied, then presumably the account on offer simply isn't an account of nativism as it figures in cognitive science. Unfortunately, there are precious

\footnotetext{
If you don't like talk of conceptual truth, the issue can be reframed without serious loss in terms of assumptions that are highly entrenched-or 'non-negotiable' - within cognitive science.
} 
few truths of this sort. Indeed, as far as I can tell, there are really only two plausible candidates. The first, which I call the fundamental conceptual constraint, consists in the following claim:

FCC: If a cognitive structure is innate, then it is not learned. ${ }^{4}$

This condition is so widely accepted among cognitive scientists and it's role in inference to and from innateness claims so pervasive, that any account of innateness that cannot accommodate it is surely unsatisfactory. ${ }^{5}$ This is not to say, of course, that nativism is incompatible with the existence of learning. Indeed, contemporary nativists invariably accept that human beings learn lots of things. Rather, the point is that the sine qua non of an innate cognitive structure is that it is not learned.

The second conceptual constraint, while perhaps less widely acknowledged in the cognitive science community, is nevertheless one that, all else being equal, an account of nativism ought to satisfy. According to this negative conceptual constraint:

NCC: The claim that a cognitive structure is innate does not imply that no environmental factors contribute to the acquisition of the structure.

This claim is little more than a banal truism. After all, it is very plausible to claim that all human characteristics depend on at least some interactions with things external to the organism (Block, 1981, p. 281). A fetus does not develop legs, arms and skin, for example, without exchanging oxygen, water and nutrients with its mother, and a neonate does not develop teeth and hair without breathing, drinking and eating. But all of this involves interaction with an environment external to the organism. So, if the notion of innateness is to be at all interesting, then it must satisfy NCC. Nevertheless, critics of nativism do not always respect this point. So, for example, in their recent and highly influential book, Rethinking Innateness, Jeffrey Elman and his co-authors maintain that a trait is innate just in case it is 'the product of interactions internal to the organism' and then proceed to reject the claim that there are innate representations on the grounds that the development of representations is sensitive to environmental factors (Elman et al., 1996, p. 23). Despite such occasional mistakes by non-nativists, however, the acceptance of NCC is so pervasive in cognitive science-especially among nativists—-that any critique

\footnotetext{
Contrapositively: If a cognitive structure is learned, it is not innate.

It should be stressed that the notion of learning is itself an extremely vexed one. I return to this issue in section 3.3.2. For present purposes, however, I wish merely to note that whatever accounts of innateness and learning one provides, it needs to turn out that 'innate' and 'learned' are related in such a way that a (token) psychological structure cannot be both innate and learned.
}

(c) Blackwell Publishers Ltd. 2002 
which fails to take it into account only succeeds in refuting a straw man-a position that is easily undermined but accepted by no one. ${ }^{6}$ For this reason, I assume that, ceteris paribus, a satisfactory account of nativism should respect the NCC.

\subsection{Argument Constraints}

A second important kind of constraint on a satisfactory account of nativism in cognitive science - the argument constraint-is that, all else being equal, we should prefer an account on which the central arguments for nativist claims turn out to be at least prima facie relevant to establishing such claims. ${ }^{7}$ The motivation for this desideratum consists in a fairly straightforward application of a principle of charity. Unless we assume that the arguments which nativists invoke are at least prima facie relevant to establishing innateness claims, we are forced to conclude that nativists are extremely confused indeed. But such a conclusion is implausible. Though Chomsky, Fodor, Spelke and other nativists in cognitive science may be wrong, they are surely not so hopelessly confused that their arguments are not even prima facie relevant to establishing the claims that they purport to defend.

What arguments should concern us in articulating this constraint in more detail? There are, of course, many arguments that have been invoked in support of nativist conclusions. The following three, however, really ought to be accommodated by a satisfactory account of innateness both because their relevance to establishing nativist conclusions is beyond serious doubt and because they are so frequently invoked.

The first and most well known of these three arguments, is the Chomskian poverty of the stimulus argument (Chomsky, 1980). While I assume that the reader is familiar with arguments of this kind, the rough idea is that they purport to show that some psychological structure-e.g. knowledge of grammar-is, in a sense, too rich to have been learned from experience and, hence, must be innate. Though such arguments are most familiar from discussions of language acquisition and are frequently invoked in support of the claim that humans possess an innate universal grammar, it is possible to apply them to other domains, such as theory of mind. ${ }^{8}$

6 Thus, for example, Fodor maintains that 'Linguistics is the locus classicus of recent nativist theorizing. But linguists might reasonably claim to be the only cognitive scientists who have ever taken the interactionist program completely seriously' (Fodor, 1998b, p. 146). See Chomsky (1980), Fodor (1981), Fodor (1998a) and Scholl and Leslie (1998) for further expressions of the nativist commitment to NCC.

7 When speaking of 'central arguments' I mean ones that are prominent in the cognitive science literature and which are widely considered to be relevant to establishing nativist claims.

8 It worth pointing out that POS arguments come in a variety of forms. One important distinction is between: (a) a posteriori POS arguments which are based on specific empirical claims about the inputs to and outputs from the acquisition process and (b) a priori POS arguments which do not depend on such empirical details but instead seek to infer the existence of innate cognitive structure from a consideration of the logical structure of the 
A second and closely related kind of argument that an account of nativism ought to accommodate is what we might call the argument from early development. Though perhaps merely a particular variant of the poverty of the stimulus argument, ${ }^{9}$ its deployment in developmental psychology is so pervasive that it is worth treating separately. So, for example, arguments from early development figure prominently in the work of Spelke, Carey and Wynn (Wynn, 1992; Carey and Spelke, 1994; Karmiloff-Smith, 1992). These arguments take roughly the following form. First, it is observed under experimental conditions that infants possess certain capacities-e.g. the capacity to distinguish between the sizes of different classes. Second, it is argued that the capacity in question is best explained by positing some kind of cognitive structure-e.g. number concepts or bodies of information about numbers or a counting mechanism of some kind. Finally, it is argued that because the capacity emerges exceedingly early in development, it is implausible to claim that the structure which subserves it was learned in the time available. Thus advocates of this kind of argument conclude that the structure in question is (probably) innate.

A final argument that a satisfactory account of nativism ought to accommodate is what we might call, for want of a better name, the universal acceptance of nativism argument. Ned Block articulates the argument in the following manner:

No organism can learn without a mechanism that accomplishes this learning. Hence at least one learning mechanism must be innate (if only a mechanism for acquiring other learning mechanisms). (Block, 1981, p. 279)

Block thus concludes that 'even Skinnerian behaviorists must (and often do) allow that there is an innate learning mechanism' (ibid.). Of course, this argument is not supposed to show that there is lots of innate psychological structure. Rather it is intended to show merely that every psychological theory is committed to at least some innate structure. But, perhaps because of the modesty of this conclusion, the argument has extremely wide acceptance among both nativists and their opponents. Indeed it is so widely accepted that its status appears to be viewed as little more than a banal truism among virtually all those engaged in debate over nativism. Thus Quine- no friend to nativism-

acquisition-task itself (Cowie, 1999). For our present purposes, however, this is not a distinction that need concern us. See Cowie (1999) for a recent discussion of poverty of the stimulus arguments.

9 Nonetheless, they differ from the original Chomskian arguments in at least two respects. First, they draw far more heavily on detailed experimental findings from the developmental psychological literature. Second, they do not maintain that there is insufficient information in the environment to permit the learning of particular psychological structures. Rather they maintain that, irrespective of what information is available, the infant has insufficient time to learn the structure in question in the period that, as a matter of fact, it takes to acquire the structure.

(C) Blackwell Publishers Ltd. 2002 
appears to make much the same point when arguing that even 'the behaviorist is knowingly and cheerfully up to his neck in innate mechanisms' (Quine, 1969). Needless to say, nativists agree.

\subsection{The Logical Geography Constraint}

A third constraint on accounts of nativism in cognitive science is that they should not distort the logical geography of the debate. Specifically, ceteris paribus, an account should preserve the standard categorization of central figures. For instance, Piaget and Skinner should, all else being equal, be categorized as nonnativists and Fodor and Chomsky as nativists. This is a very plausible constraint. After all, if an account were, for example, to categorize Chomsky as a nonnativist and Piaget as a nativist, then, in the absence of strong reason to adopt such a revisionist stance, we would surely conclude that the proposal simply failed to capture nativism as it figures in cognitive science.

\subsection{The Significance Constraint}

A final constraint on a satisfactory account of nativism is that, all else being equal, it should explain the significance of debate over nativism in cognitive science. In other words, it should explain why nativism matters to cognitive scientists. I have two main reasons for proposing this constraint. First, the fact that many prominent psychologists and cognitive scientists have invested so much time trying to determine which cognitive structures are innate, provides us - at least presumptively-with reason to think that this dispute is an important one. Second, unless we possess an explanation of why debate over nativism is important, it becomes extremely unclear why we should continue to debate such matters at all. If, in other words, we are to defend the practice of inquiring about the innate structure of the human mind, then we ought to possess some grounds for thinking that it is an important issue.

To summarize: I have argued that a satisfactory account of nativism in cognitive science should (at least ideally) meet the above four constraints or conditions of adequacy. With this in mind, it's time to consider some accounts of nativism and see how well they fair in meeting these constraints. I will not attempt to provide a comprehensive critique of all the extant accounts. That would be too large a task and, in any case, virtually all of these proposals have already been ably criticized elsewhere. ${ }^{10}$ Instead, I propose to focus primarily on what is surely the most popular, contemporary approach to understanding innateness - especially among philosophers of biology — what might be called the invariance approach.

10 See, for example, Ariew 1996 and 1999; Cowie, 1999 Chapter 1; Griffiths and Gray, 1992; Griffiths and Sterelny, 1999 and Wimsatt, 1999. 


\section{Invariance Accounts of Innateness}

The general idea behind all invariance accounts is to define innate traits as those whose development is invariant with respect to some appropriate range of developmental environments. Innate traits are ones that are highly invariant and those that are insufficiently invariant are not innate. My main objective will be to highlight how this approach fails to accommodate many of the constraints outlined in the previous section and to identify a pattern of failure that warrants the adoption of an alternative account. But before doing so, it would be helpful to consider briefly why such accounts are so popular.

\subsection{Two Routes to the Invariance Account}

There are at least two routes to the adoption of an invariance account of innateness. The more direct route consists in the straightforward invocation of invariance in order to characterize innateness. The indirect approach is mediated via a complex discussion of genetic determination.

1. The Direct Route On the face of it, the invariance approach is a plausible way of fleshing out much of what we are inclined to say about the notion of innateness. One very natural starting point for trying to develop an account of innateness is the intuitive dichotomy between what is innate and what is acquired. Indeed, one might think that, at least as a first pass, what it is for a structure to be innate is for it to be non-acquired. Leaving things here, however, would surely be unsatisfactory since there are clearly lots of different things that one might mean by 'acquisition'. Unless we are told what the appropriate notion is, very little progress has been made.

Moreover, on some perfectly reasonable characterizations of 'acquired', the claim that a structure is innate just in case it is not acquired is clearly false. Consider, for example, what we might call the baseline conception of acquisition:

A (token) structure $\mathrm{S}$ is acquired by a particular object $\mathrm{O}$ (e.g. an organism) just in case $\mathrm{O}$ fails to possess $\mathrm{S}$ at all times prior to time $\mathrm{t}$ but possesses $\mathrm{S}$ at $\mathrm{t}$.

Though this notion of 'acquisition' is a perfectly sensible one, ${ }^{11}$ it is clearly insufficient for drawing the innate/noninnate distinction since, in this sense, all cognitive structures are acquired. Human cognitive structures are traits of biological organisms and it is exceedingly plausible to maintain that there is a point sufficiently early in development when humans lack any cognitive traits or structures whatsoever. (A blastocyst, for example, is a ball of cells with no cognitive traits.) In which case, humans must acquire (in the baseline sense)

11 Indeed, I will utilize it in developing my positive account of innateness.

(C) Blackwell Publishers Ltd. 2002 
all cognitive structures. So, if innate traits are the ones that are not acquired in the above sense, then there are obviously no innate traits whatsoever and nativism is obviously false. What, then, is all the fuss over nativism about?

Of course, this does not mean that innateness cannot be characterized in terms of some notion of (non-) acquisition. All that follows is that something more substantial than the baseline conception is required. But what more is needed? What should be added in order to develop a satisfactory account of innateness? In effect, this is the issue that all contemporary accounts of innateness attempt to answer. And on the face of it, the invariance approach appears to address this question in a plausible manner. What it says (roughly) is that innate structures are acquired (in the baseline sense) in all of a large range of developmental environments. As it were, what it is to be innate on this view is to be robustly acquired. This is an idea that arguably goes back at least as far as Descartes and has been explored more recently by, among others, Ariew (1996 and 1999), Sober (1999) and Stich (1975).

2. The Indirect Route The second and more indirect route to the adoption of the invariance account goes via a complex debate over the notion of genetic determination and its connection to the concept of innateness. On the face of it, it is enormously plausible to characterize innateness in terms of genetic determination. Thus, for example, Ned Block has suggested that one will not go far wrong if one understands 'the content of knowledge or capacities to be innate just in case the knowledge and capacities are ... determined by the genes, rather than learned or otherwise determined by the environment' (Block, 1981, p. 280). But how should we understand this notion of genetic determination? Historically, there have been two dominant approaches:

a. Genetic determination should be characterized in terms of genetic causation. Traits are genetically determined if they are caused (in the appropriate way) by genetic factors.

b. Genetic determination should be understood in terms of genetic representation. Genetically determined traits are ones that are represented in the genes.

But, as has been frequently observed, neither of these approaches has met with much success. One cannot, for example, adopt the obvious causal account of genetic determination - that a trait is genetically determined just in case it is caused by genetic factors alone-because no biological trait is caused in this way. All traits causally depend on both genetic and environmental factors. Moreover, other attempts to characterize genetic determination in terms of genetic causation have been similarly unsuccessful. (See Block, 1981 and Griffiths and Gray, 1992 for discussions of this problem.)

Nor have attempts to provide representational accounts of genetic determination proven any more successful. For although it is superficially plausible to 
claim that genetically determined traits are represented in the genes, there appears to be no appropriate notion of representation that will play the role required by such an account. (See Oyama, 1985; Griffiths and Gray, 1992 and Griffiths and Sterelny, 1999.) Suppose, for example, one adopts a straightforward causal-covariational account of representational content according to which $\mathrm{R}$ represents $\mathrm{O}$ just in case $\mathrm{R}$ causally covaries with $\mathrm{O}$. The problem with this view is that it seems overwhelmingly likely that all traits causally covary with both genetic and environmental factors. In which case, all traits will be represented in both the environment and the genome (Griffiths and Sterelny, 1999).

Here's where the notion of developmental invariance enters the discussion. Given that attempts to explicate genetic determination in terms of causation and representation have proven so unsuccessful, perhaps we can analyze it in terms of developmental invariance. Thus, for example, Philip Kitcher maintains that our genetically determined characteristics are "those that would persist under those changes in genetic background and in environment that allowed us to survive and thrive' (Kitcher, 1996, p. 243). But if a trait is innate just in case it is genetically determined and a trait is genetically determined just in case it is sufficiently invariant with respect to environmental change, then we end up with an invariance account of innateness.

\subsection{On the Plausibility of Invariance Accounts of Innateness}

How plausible are invariance accounts of innateness? The answer, I maintain, is that they are not at all plausible. In arguing for this claim, I shall focus primarily on one of the most recent and most plausible of the many versions of the invariance account-one defended by Eliot Sober. It should be kept in mind, however, that, as far as I can tell, my objections apply mutatis mutandis to all extant versions of the invariance proposal.

Sober formulates his account of innateness in the context of discussing the contrasts between what he views as the 'traditional philosophical concept of innateness' and, prima facie, related notions that figure in contemporary biology. Having outlined a range of important putative differences, ${ }^{12}$ he makes the following suggestion:

In view of all this, it is a reasonable hypothesis that the most that can be salvaged from the ancient concept of innateness is this: a phenotypic trait is innate for a given genotype if and only if that phenotype will emerge in all of a range of developmental environments (Sober, 1999).

12 He observes, for example, that the traditional notion is closely tied to the concept of universality whereas the contemporary biologists notion is not.

(C) Blackwell Publishers Ltd. 2002 
The question of what counts as an appropriate range of environments is deliberately left open. ${ }^{13}$ But judging from Sober's own examples, it is traits that are acquired in exceedingly wide ranges of environments that will to be counted as innate. So, for example, a species of bird that acquires a characteristic song in all of a very large class of developmental environments will count as having an innately specified song repertoire. By contrast, a species that only acquires its characteristic song in a highly restricted range of environments-e.g. those in which it is sung by conspecifics-won't count as having an innate song repertoire.

Sober clearly thinks that, at least from the perspective of contemporary biology, the notion of innateness is best articulated in terms of developmental invariance. But his proposal suffers from a number of serious deficiencies as an account of nativism in cognitive science. ${ }^{14}$ First, and perhaps most seriously, it's entirely unclear how it is supposed to satisfy the fundamental conceptual constraint. According to this constraint, if a psychological structure is learned, then it's not innate. But why, on Sober's account, should this be true? Consider, for example, the belief that water is wet. It is very plausible to maintain that pretty much every human being acquires this belief. Moreover, it is not implausible to claim that we learn it. ${ }^{15}$ Indeed, given that there are samples of wet water in all the environments in which human beings live, it is hard to see why the belief that water is wet could not be learned by a general-purpose inductive mechanism in all of these environments. But if this is so, then presumably the belief that water is wet could be both learned and invariant across an exceedingly wide range of developmental environments. In which case, it could be both innate and learned on Sober's account.

Of course, one could respond to this objection by pointing out that there might be a way to fix the range of environments, so as to rule out the above example. But this response misses the point. Of course, there may be a way to gerrymander the environments in this fashion, but merely admitting this

13 Indeed, Sober has good reason for leaving this issue unaddressed, namely: he thinks that it can only be determined in a pragmatic and context-sensitive manner. Here is what he says on the matter. 'What counts as the appropriate range of environments is left open on this proposal. Perhaps there is a uniquely correct answer to this question; then again, maybe the range is determined pragmatically. It is difficult to see how the latter conclusion can be evaded' (Sober, 1999). Though I suspect that this pragmatist position is the most plausible one for an advocate of the invariance approach to adopt, it does not address the problems that I level against Sober's proposal. The question that concerns us is not whether there is a single range of environments relevant to the evaluation of all innateness claims but whether or not there is any range E-presumably determined by contextual and pragmatic factorsthat, when plugged into Sober's account, will yield a plausible account of nativism in cognitive science.

14 Though I wish to remain neutral on the issue of whether or not Sober succeeds in capturing some notion of innateness that is used (or required) by contemporary biology.

15 In fact, in order to run this argument, I need only defend the weaker claim that it is possible that we learn this belief. 
possibility does not explain why the fundamental conceptual constraint is true. It merely issues a promissory note. Moreover, it is one that no one has, at present, any idea how to cash. We do not know, in other words, how to fix the range of environments in the appropriate fashion. In which case, we currently possess no idea how Sober's account accommodates the fundamental conceptual constraint.

Another problem with Sober's account of innateness is that it does not appear to satisfy the argument constraint. In order to do so it needs to explain why the arguments discussed in 1.2 are at least prima facie plausible arguments for nativist claims. But it does not seem to meet this challenge. In order to illustrate the point, consider the argument for the universal acceptance of nativism. This argument purports to show that all psychological theories are committed to the existence of at least some innate psychological structure. But why should this be true on Sober's account of innateness? Why, in other words, should the mere fact that not every psychological mechanism can be learned, provide support for the claim that the emergence of some psychological mechanisms is invariant across an exceedingly wide range of developmental environments? As far as I can see, there is no reason. Of course, if one were to make the assumption that unlearned traits tend to be highly invariant, then the inference would go through. But it is far from clear that there is any reason to make such an assumption. Bruises, haircuts and long toenails, to name only a few examples, are not learned, but none of them are highly invariant with respect to developmental environments. Nor, to my knowledge, is there any good reason to accept the more restricted claim that unlearned psychological structures tend to be highly invariant. Indeed, if the Chomskian claim that natural languages are not learned is correct, then there would appear to clear cases of psychological structures - i.e. grammars for natural languages, such as French and English - that are neither learned nor highly invariant. ${ }^{16}$

A final problem with Sober's invariance account is that it appears to violate the logical geography constraint by distorting the structure of the debate over nativism in cognitive science and by incorrectly characterizing the positions endorsed by some prominent theorists. On Sober's view, two traits can differ with respect to whether or not they are innate only if one is more developmentally invariant than the other. But it is far from clear that this correctly characterizes the nature of the dispute between nativists and their opponents in cognitive science. In order to do so, it would need to be the case that all such disputes ultimately turn on disagreements over the invariance of cognitive structures. But this is simply not the case. Consider, for example, the dispute between Piaget and Chomsky over the nature of cognitive development. ${ }^{17}$

16 Similarly, if Fodor's (1981) claim that many of our concepts are 'triggered' is correct, then it would appear that many of our concepts will be both unlearned and not invariant. See below for more discussion of triggering.

17 See Piattelli-Palmarini (1979) for a comprehensive overview of this debate.

(C) Blackwell Publishers Ltd. 2002 
Clearly, these prominent theorists disagreed over the extent to which the structure of the human mind is innately specified. But it is abundantly clear that the dispute did not center on issues about the developmental invariance of cognitive structure. Chomsky, of course, views much of human cognitive development as highly invariant. But so too did Piaget. In fact, one central feature of his view was that many structures-e.g. the object concept-are highly invariant even though there are not innately specified. Indeed, according to Piaget, not only do all normal children acquire such non-innate structures but, in doing so, they all conform to much the same developmental timetable. ${ }^{18}$ In which case, on Sober's account, Piaget would appear to be a nativist!

As we have seen, Sober's invariance account of innateness is subject to a range of serious objections. Moreover, I maintain that my critique generalizes to all extant versions of the invariance account. To my knowledge, all such accounts confront problems with accommodating the FCC, the argument constraint and the logical geography constraint. But why is this? What kind of diagnosis can we offer for these failures? Here is a suggestion. The fundamental flaw to which all invariance accounts are subject is that they attempt to explain the central features of innateness solely in terms of a mapping relation between genotypic and phenotypic traits, without imposing any substantive constraints on the mechanisms or processes in virtue of which such mapping relations obtain. What they all ignore, in other words, is the question of what explains the existence of such invariant mappings. It is precisely because they ignore this explanatory issue that invariance accounts violate the FCC by permitting the possibility of innate but learned cognitive structures. Moreover, the failure of invariance accounts to address this explanatory issue also results in its failure to identify the true locus of debate over nativism and its tendency to render familiar arguments for innateness claims irrelevant. If we are to produce a satisfactory account of nativism in cognitive science, I maintain that we need to place this explanatory issue at the very heart of our account. In the remainder of this paper I explore just such an approach—what I call the primitivist account of nativism.

\section{The Primitivist Account of Nativism}

In order to lay out of the primitivist account of nativism, I first need to outline the central notion invoked by the proposal - the notion of a psychological primitive. Having done so, I then explain how this notion can be used to address the problems of special and general nativism. Finally, I compare and contrast the resulting primitivist proposal with a number of related ones in order to clarify it further.

18 See Piattelli-Palmarini, 1979, p. 58 for an expression of Piaget's view that non-innate cognitive structures can be highly invariant. 


\subsection{Psychological Primitives}

The term 'primitive' is used in a variety of ways in the literature on nativism. In particular, it is frequently deployed in order to make claims about the relative structural complexity —or lack thereof-of certain cognitive structures. So, for example, in discussions of concept nativism, it is frequently used in order to denote concepts that do not have other concepts as constituents (Fodor, 1981; Laurence and Margolis, 1999). In what follows, however, I use the term 'primitive' in a nonstandard fashion. Rather than using it in order to express a structural notion-one that concerns the relative complexity of cognitive structures-I use it in order to express what might be called an explanatory notion of primitiveness. As I deploy the term, for a cognitive structure to be primitive is for there to be no theory of a certain kind that explains its acquisition. Specifically, let us say that a psychological structure S-e.g. a concept, belief, learning mechanism or module-is a psychological primitive just in case:

1. $\mathrm{S}$ is a structure posited by some correct scientific psychological theory.

2. There is no correct ${ }^{19}$ scientific psychological theory that explains the acquisition of S (in the baseline sense of 'acquisition'). ${ }^{20}$

According to this definition, to say that a cognitive structure $\mathrm{S}$ is primitive is to claim that, from the perspective of scientific psychology, $\mathrm{S}$ needs to be treated as one whose acquisition has no explanation. For although primitive cognitive structures are presumably acquired in the (baseline) sense that they are not possessed by an organism at one time but are possessed at some later time, psychology fails to provide an explanation of how they come to be possessed. Of course, this is not to say that there is no theory whatsoever that explains the acquisition of S. It may be the case and, indeed, presumably is the case that some other branch of science-e.g. neurobiology or molecular biology—can

19 What is it for a scientific psychological theory to be correct? Though this is a natural question to raise given that the notion of a psychological primitive is partially defined in terms of the notion of a correct theory, it is not one that need concern us here. What it is for a scientific psychological theory to be correct is just a specific instance of the more general question of what it is for a scientific theory - any theory - to be correct. This is, however, surely a general issue in the philosophy of science and not a problem that is in any way peculiar to the philosophy of psychology, let alone the present enterprise of providing an account of nativism in cognitive science. Both for this reason and because nothing I have to say turns on the details of how we address this issue, I set it to one side.

20 Of course, when using the phrase 'there is no correct scientific psychological theory that explains the acquisition of S', I do not mean that we have not discovered such a theory. Such a view would make being a psychological primitive relative to the current state of psychological theorizing. Rather, I mean that there is no such theory to be discovered. On this view, whether or not $\mathrm{S}$ is psychologically primitive is not relative to the current state of theorizing within psychology. Even if we never actually discover a correct scientific psychological theory for the acquisition of $\mathrm{S}$, it will still fail to be psychologically primitive, if there were some correct, scientific, psychological theory to be discovered. 
provide an explanation. It's just that psychology cannot furnish us with such a theory.

It would be useful to consider how this notion of a psychological primitive applies to some familiar cases from the literature on concept acquisition. According to a highly influential cluster of theories, much of our conceptual repertoire is learned via an inductive process of hypothesis formation and testing (Bruner et al., 1956). Suppose that such theories are correct. Then the concepts so acquired are not psychologically primitive in the above sense because there is a correct psychological explanation of how they are acquired. Since hypothesis formation and testing is a paradigmatic example of a psychological process, if it were the case that concepts are acquired in this way, then they would not be psychologically primitive. By contrast, suppose that there are concepts that are acquired via what is often called a triggering processroughly, a 'brute-causal' process that is not mediated by any psychological states (Fodor, 1981). ${ }^{21}$ Given that triggering is, almost by definition, a nonpsychological process, a concept so acquired will be psychologically primitive in the above sense. That is, such a concept will be psychologically primitive because no scientific psychological theory will provide a correct explanation of how it was acquired.

\subsection{The Primitivist Response to the Problems of Special and General Nativism}

With this rough specification of the notion of a psychological primitive in hand, we are now in a position to provide a first pass at formulating an account of nativism in cognitive science that addresses the problems of special and general nativism. Addressing the problem of special nativism, you may recall, requires us to say how we ought to understand claims about the innateness of specific (kinds of) cognitive structure-i.e. what it is to be a nativist with respect to some specific (kind of) cognitive structure. To a first approximation, ${ }^{22}$ then, the account I want to defend is that a psychological structure is innate just in case it is a psychological primitive. So, for example, the claim that there is an innate module for language acquisition amounts to the claim that there is a psychologically primitive module for language acquisition. While the module is a psychological structure posited by some correct scientific psychological theory, there is no correct, scientific, psychological explanation of how we come to possess it. Or, roughly equivalently, though the module is a psycho-

21 The notion of a triggering process is a notoriously vague and slippery one. Indeed, it's hard to find much agreement on how it should be understood aside from the more-or-less stipulative claim that triggering is a 'brute-causal' process of acquisition that is not mediated by any psychological states. See Fodor (1981) and Cowie (1999) for further discussion of what triggering is.

22 In section 5, I refine this proposal in order to meet objections. 
logical mechanism, there is no psychological process or mechanism that is responsible for its acquisition.

Let's turn to the problem of general nativism. This problem requires us to address the question 'In what does the general distinction between nativism and nonnativism in cognitive science consist?' Though there are no doubt a number of issues that divide nativists and their opponents, I maintain that a central-perhaps the central-point of dispute in contemporary cognitive science concerns the size of the inventory of psychologically primitive structures. Nativists posit lots of psychologically primitive cognitive structure. By contrast, nonnativists maintain that there is far less. Of course, this distinction admits of degree and, hence, the extent to which one is a nativist or nonnativist can also admit of degree. But this is as things should be. Chomsky is, for example, clearly a nativist to some interesting extent even though Fodor-at least in some of his moods - is more nativistically inclined than Chomsky is.

\subsection{Further Clarifications}

The above response to the problems of special and general nativism is clearly related to other claims that have been made in discussions of innateness. Specifically, it bears a resemblance to (a) the claim that innate structures are just the ones that are not learned and (b) Fiona Cowie's recent claim that one central strand in nativist theorizing denies that there are naturalistic explanations of how various psychological structures are acquired (Cowie, 1999). In order to clarify further the primitivist account, it will be useful to compare it with these claims. Moreover, in doing so, I'll make some brief comments on how, for the purposes of developing an account of nativism, I propose to construe the notion of a scientific psychological theory of acquisition.

3.3.1 Primitivism and Non-Naturalism. In her recent book, What's Within, Fiona Cowie defends a view of nativism that is, in certain respects, very similar to primitivism. In brief, according to Cowie, one central strand of nativist thought - which she calls the mystery hypothesis-is that 'the mind is much more mysterious than is dreamed of in the overly simplistic natural philosophy of the empiricist' (Cowie, 1999). More specifically, she claims that the mystery hypothesis is a form of non-naturalism according to which we cannot provide any scientific, causal-explanatory account of the acquisition of (at least some) concepts and beliefs.

There are, I think, a number of important virtues to Cowie's proposal. First, it is not implausible to claim that it succeeds in capturing a central issue that divided enlightenment rationalists, such as Leibniz and Descartes, from their empiricist counterparts. Second, I think that Cowie is entirely correct to characterize nativism as a largely negative doctrine that involves denying the availability of certain sorts of explanation. Nevertheless, as an account of nativism in cognitive science, primitivism is preferable since the mystery hypothesis fails to capture any position endorsed in the contemporary debate over innateness. 
Cowie's principal candidate for a contemporary mystery theory is Jerry Fodor's view of concept acquisition. But this is prima facie implausible given Fodor's frequent and sometimes strident endorsement of naturalism (Fodor, 1987). Moreover, Cowie's argument for the claim that Fodor is a mystery theorist is not convincing. What she does succeed in showing is that he denies the existence of psychological explanations of concept acquisition-'that explaining concept acquisition is none of the psychologist's business' (Cowie, 1999, p. 107). It does not follow from this, however, that Fodor is a mystery theorist in the sense outlined earlier. All that follows is that he endorses a form of primitivism about concepts. ${ }^{23}$ Perhaps this is all that Cowie really wants to claim. ${ }^{24}$ But there is another view that can be found in her work that appears to commit her to a more radical interpretation of Fodor's position. On this interpretation, his view suggests that 'it is the metaphysicians and not the scientists who get to explain concept acquisition' (Cowie, 1999, p. 111).

The evidence for this more radical interpretation is uncompelling, however. The first piece of evidence is that in Concepts, Fodor dismisses the claim that natural selection can provide a satisfactory account of concept acquisition. From this Cowie concludes that, according to Fodor, biology cannot explain how we get our concepts (p. 111). But there is much more to biology than evolutionary biology and, indeed, much more evolutionary biology than selection-based explanation. So, the mere fact that Fodor denies that natural selection can provide a satisfactory explanation of concept acquisition does not show that he rejects the existence of biological explanations of concept acquisition. There may be, for example, a neurobiological or molecular biological explanation of how concepts are acquired.

The second piece of evidence that Cowie invokes in support of her claim that Fodor is a mystery theorist, is his view that metaphysics holds the solution to what he calls the doorknob/DOORKNOB effect-the fact that we often acquire concepts (e.g. DOORKNOB) from experiences of their instances (doorknobs). But this does not really show that Fodor believes 'it is the metaphysicians - and not the scientists - who get to explain concept acquisition as well!' (p. 111). Rather, at most it suggests that Fodor thinks the doorknob/DOORKNOB effect is one that we should not expect a psychological theory of concept acquisition to explain. And, of course, this is entirely consist-

23 As Cowie puts it: 'Nothing whatsoever follows from Fodor's argument about whether or not some other science might succeed where psychology must fail. Fodor is thus at liberty, or so it seems, to follow Locke in his more moderate moods, and conclude only that we should set concept acquisition aside as being outside psychology's ambit' (Cowie, 1999, p. 109).

24 This is suggested by Cowie's claim that 'whatever one makes of Fodor's apparent flirtation in his (1998) with non-naturalism, his basic contention-and the one I propose to hold him to-is that concept acquisition is not a psychological process, and hence is not the kind of thing about which a psychological theory can or should be given' (Cowie, 1999, p. 113). 
ent with the idea that there should be a naturalistic, scientific explanation of concept acquisition.

3.3.2 Learning and Primitivism. A second proposal about nativism that bears a strong resemblance to primitivism is the familiar claim that something is innate just in case it not learned. Indeed, one might think that primitivism is merely a notational variant of this view. But clearly this depends on how we construe the notion of learning - an issue on which there is virtually no consensus. If by 'learning' we simply mean any psychological process by which psychological structures are acquired (in the baseline sense), then, on the primitivist account, being innate will be the same as being not learned. One view of primitivism, then, ${ }^{25}$ (and a view that I am happy to accept) is that it as an articulation of the appropriate sense in which innate cognitive structures are not learned. But the term 'learning' is very often used in a more restrictive fashion in order to pick out a subset of psychological processes of acquisition. For example:

1. It is not uncommon to preclude various perceptual processes-such as visual processing-from counting as forms of learning, even though they are psychological processes of acquisition.

2. Similarly, it is common for cognitive scientists to characterize learning as an inferential process whereby stimuli are used as evidence in the formation of concepts or knowledge structures (Chomsky, 1980). So, for example, Fodor suggests that learning is best viewed as a rationalcausal process in which there are 'psychological mechanisms which. . .realize an inductive logic, and [are such that] the experiences of the organism stands in a confirmation relation to the. . [structures]. . .whose availability they occasion' (Fodor, 1981, p. 283).

But neither of these restrictive uses of 'learning' is appropriate for providing an account of innateness. First, it would surely be incorrect to claim that structures acquired solely as a result of perceptual processing are innate. No-one in cognitive science, for example, would be at all inclined to say that novel visual representations are innate simply because they are the products of visual processing alone. So, the first of the above options is unsatisfactory. Similarly, characterizing innateness in terms of a rational-causal conception of learning is unsatisfactory. For although it might be plausible to characterize a cognitive structure as innate just in case it is psychologically primitive, it is implausible to characterize innateness in terms of not being rational-causally learned. Such a view would, among other things, violate the logical geography constraint.

25 Though in section $5 \mathrm{I}$ add an extra condition to my account of nativism.

(C) Blackwell Publishers Ltd. 2002 
Radical behaviorists are, for example, invariably viewed as nonnativists. But on the current proposal they will count as extreme nativists because they maintain that no inferential processes should be posited by a scientific psychology. For present purposes, then, when speaking of a cognitive structure's being psychologically primitive (and, hence, innate), I do not merely mean that it is not learned in either of the above narrow senses. Rather, I have in mind the broader claim that there is no scientific psychological explanation whatsoever of how it was acquired.

3.3.3 Scientific Psychology. The above discussion leaves open the question of what theories we should count as scientific psychological theories of acquisition. Clearly this is not an issue that can be addressed satisfactorily in the present paper. Nor, for our purposes, does anything much turn on this issue so long as we adopt a view that conforms to certain general constraints. (See below.) So, I will not attempt to defend a particular conception of scientific psychology here.

Nevertheless, it would be helpful to indicate what sorts of theories I have in mind when speaking of scientific psychological theories of acquisition. First of all, I am of course concerned with the sorts of theories that professional psychologists develop and defend as opposed to mere 'folk' explanations of the sort familiar from our everyday practice of predicting and explaining each other's behavior in intentional terms. But there are lots of different sorts of theories that professional psychologists have produced in order to explain the acquisition of psychological structures. And, to that extent, there are lots of different theories that can stake a claim - at least, presumptively - to being scientific psychological theories of acquisition. Having said that, there are two constraints that I want to impose explicitly.

First, we should impose an ontogeny constraint. We should concern ourselves with ontogenetic and not phylogenetic-i.e. evolutionary-theories about the acquisition of cognitive structure. If we counted evolutionary explanations of cognitive structure as psychological theories of acquisition, then the primitivist account would be untenable since it would imply that any cognitive structure that is produced by evolutionary pressures is not innate! Fortunately, there are at least two reasons for not counting evolutionary explanations as psychological theories of acquisition. First, given that it is almost invariably assumed-even among evolutionary psychologists - that evolutionary theories are not psychological ones, it is prima facie plausible to categorize them as non-psychological. Second, the ontogeny constraint is more or less implicit in the fact that, according to primitivism, what scientific psychology cannot provide are theories of how innate cognitive structures are acquired in the baseline sense of 'acquired'. What primitivism maintains is that if a cognitive structure $\mathrm{S}$ is innate, then scientific psychology can specify no mechanism or process in virtue of which $\mathrm{S}$ is possessed by an individual organism $\mathrm{O}$ at a given time $\mathrm{t}$, even though there is no time prior to $t$ at which $\mathrm{O}$ possesses $\mathrm{S}$. But evolutionary theories- 
whether adaptationist or not-simply do not address this question. They do not tell us which mechanism is responsible for an individual possessing $\mathrm{S}$ at $\mathrm{t}$ even though it failed to possess it at earlier times. ${ }^{26}$ Rather, it is ontogenetic theories - theories that are concerned with the development of individual organisms - that purport to address this issue. Therefore, it is ontogenetic theories and not phylogenetic/evolutionary ones that should concern us here.

Another constraint that, for the purposes of developing primitivism, we should impose on our conception of scientific psychological theories of acquisition is what might be called a non-substantiality condition. Many putative accounts of psychological explanation purport to answer the following question:

The Question of Form: What is the correct framework within which to formulate scientific psychological theories? Specifically, what sorts of processes, mechanisms and structures should be posited by scientific explanations of psychological phenomena?

Clearly, debates over this question have played a pivotal role in the development of scientific psychology. For example, the disputes between behaviorists and cognitivists and between connectionists and classical computational theorists have, in large part, concerned this Question of Form. ${ }^{27}$ Let us call accounts of scientific psychology that imply an answer to this question, substantial accounts. Such accounts are prescriptive in the sense that they advocate particular approaches to doing psychology. Moreover, they are important because, among other things, they help orient research programs by providing researchers with the conceptual resources and methodologies that enable them to identify and address major research questions.

Despite their importance, however, it would be a mistake to incorporate a substantive account of scientific psychology into the primitivist account of nativism. Suppose, for example, that we were to incorporate a classical computational account of psychology. On such a view, a cognitive structure $\mathrm{S}$ would be innate if there were no correct classical computational account of how $\mathrm{S}$ was acquired. But this proposal is absurd. First, it violates the logical geography

26 There is, at present, considerable discussion in the philosophy of biology regarding the question of whether or not evolutionary explanations (a) explain why individual organisms possess specific traits or (b) merely explain why traits get distributed within populations in the way that they do. (See, for example, Sober, 1995 and Neander, 1988.) I favor option (b). But notice that even if (a) were correct, evolutionary explanations would still fail to address the question that concerns us here. It is one thing to explain why $\mathrm{O}$ possesses $\mathrm{S}$, as opposed to not possessing it, and quite another to provide an explanation of how it is that $\mathrm{O}$ comes to possess $\mathrm{S}$ at $\mathrm{t}$, given that they lacked it prior to $\mathrm{t}$.

27 Indeed, even accounts that do not appear to be explicitly concerned with the Question of Form, such as Cummins' functionalist account, turn out on closer inspection to partially concerned with this matter. 
constraint by implying that theorists — such as radical behaviorists-who reject the computational approach and deny the correctness of such explanations are extreme nativists. Second, it implies that if classical computationalism is entirely false and there are no correct classical explanations of human behavior and cognition, then all cognitive structures are innate! But, of course, this is wrong. Clearly no such consequences follow from the falsity of classicism.

The obvious solution to these problems is to adopt a conception of scientific psychology which satisfies the following Non-Substantiality Condition: In developing the primitivist account of nativism, we should adopt a non-substantial account of psychological theories of acquisition-one that does not imply an answer to the Question of Form. The crucial feature of non-substantial views of psychology is that they are liberal in the sense that they can count lots of different sorts of theories as scientific psychological ones. And though the task of spelling out in detail a non-substantial account of scientific psychology is nontrivial, for present purposes, I am happy to accept any proposal that is sufficiently liberal to accommodate the approaches to psychological theorizing that have figured centrally in the history of debates about the innateness of cognitive structure. That is, we need an account of scientific psychology according to which, for example, behaviorism, Piagetian constructivism, classical computationalism, Humean associationism and connectionist approaches all turn out to be forms of scientific psychology.

\section{Satisfying the Constraints}

In section 1, I outlined a range of desiderata that an account of nativism in cognitive science ought to satisfy. I then argued, in section 2 , that some prominent extant accounts of innateness fail to do so. The question that I address in this section is: Does primitivism do a good job of satisfying these desiderata? The answer is, I maintain, 'Yes.' Furthermore, I maintain that this is a notable virtue of the view. In order to argue for this claim, let's look, in turn, at each of the desiderata.

\subsection{The Conceptual Constraints}

Primitivism easily meets the conceptual constraints that I discussed earlier. First, it clearly meets the fundamental conceptual constraint - that an account of nativism ought to explain why if a structure is learned, then it is not innate. The reason for this should be obvious. Though there are considerable problems with how to understand what learning is, one thing that's abundantly clear is that, however one might characterize learning, it had better turn out that it is a psychological process. This claim is, as far as I can tell, universally accepted amongst cognitive scientists and psychologists. But if this is so, then learned cognitive structures cannot be psychologically primitive and, hence, are not innate on the primitivist proposal. 
Primitivism also satisfies the negative conceptual constraint. According to this constraint, the claim that a cognitive structure is innate does not imply that no environmental factors contribute to the acquisition of the structure. But since primitivism is neutral about the extent to which the environment contributes to the acquisition of innate structures, it clearly does not imply that environmental factors make no contribution. So, primitivism appears to meet both of our conceptual constraints.

\subsection{Logical Geography Constraints}

Primitivism also satisfies the logical geography constraint outlined earlier. According to this constraint, a satisfactory account of nativism should preserve the standard categorization of central figures in debates over nativism. So, for example, a satisfactory account should categorize Piaget and Skinner as nonnativists and Chomsky and Fodor as nativists. The primitivist proposal seems to get this right. Piaget, for instance, clearly turns out to be a non-nativist since, as Karmiloff-Smith (1992, p. xiii) observes, he famously maintained that only 'a minimum innate underpinning for subsequent domain-general learning' was required by an adequate developmental psychology — sensory reflexes and the processes of assimilation, accommodation and equilibration. Piaget was, in other words, committed to the claim that the acquisition of virtually all of our psychological structures could be explained by positing only a highly restricted range of cognitive structures that are not themselves acquired by psychological processes or mechanisms. This very much places Piaget at the non-nativist end of the spectrum according to the primitivist proposal. Similarly, although Skinner's behaviorism, with its radically divergent conception of psychological structure, makes him a little difficult to categorize, it is well known that he aimed to explain human behavior by positing only a highly restricted range of unlearned psychological structures. In which case, he also turns out to be a non-nativist on the primitivist proposal.

By contrast, both Chomsky and Fodor clearly turn out to be nativists on the primitivist account since they both posit large amounts of psychologically primitive structure. Chomsky maintains, for example, that in addition to whatever innate, general-purpose learning mechanisms we may possess, we also have a universal grammar and various modules (e.g. for face recognition, syntax and phonology) that are not themselves acquired by psychological processes (Chomsky, 1988). ${ }^{28}$ Thus Chomsky posits more psychologically primitive structures than Piaget and Skinner and, consequently, is more nativistic in his views than they are. In a similar fashion, Fodor posits a number of modules for language and for perceptual processing that he clearly thinks are not acquired by psychological processes (Fodor, 1983). Moreover, in some of his

28 This is very much indicated by Chomsky's tendency to maintain that such cognitive structures are not learned but 'grow' or 'mature' (Chomsky, 1980 and 1988).

(C) Blackwell Publishers Ltd. 2002 
moods he is inclined to maintain that virtually all of our lexical concepts are not acquired by psychological processes or mechanisms (Fodor, 1981, 1998a). Thus primitivism correctly characterizes Fodor as a (radical) nativist.

\subsection{The Argument Constraints}

Primitivism also satisfies the argument constraint by explaining why all three arguments discussed in 1.2 are relevant to establishing nativist conclusions. First, on the primitivist account, the poverty of the stimulus arguments turns out to be relevant to establishing nativist conclusions. This is because it is very natural to interpret such arguments as attempting to show that certain kinds of structure-e.g. specialized linguistic knowledge-are not acquired by psychological processes. In order to illustrate this point, consider Chomsky's versions of the poverty of the stimulus argument for the existence of a universal grammar. These arguments clearly purport to show that the acquisition of an internally represented grammar for natural language requires us to posit a specialized body of linguistic knowledge - a universal grammar. Moreover, Chomsky and his followers clearly think that universal grammar itself is not acquired by any psychological process but rather must be posited as a psychological structure whose acquisition is not explained by any psychological theory. ${ }^{29}$ Thus Chomsky maintains that we should " "factor out" certain general principles that govern rule application and assign them to the initial state of the language faculty' (Chomsky, 1991, p. 22). In short: we should treat this set of principles - the universal grammar-as psychologically primitive.

Second, arguments from early development turn out to be relevant to establishing nativist conclusions on the primitivist story. Such arguments purport to show that certain cognitive structures-e.g. number concepts, knowledge about the behavior of physical objects etc.- are not learned because the infant has insufficient time to acquire them by any known learning process. But since learning is the paradigmatic example of a psychological process of acquisition, it follows that arguments from early development provide support_-albeit nondemonstrative support-for the claim that some structures are psychologically primitive and, therefore, innate.

Finally, the primitivist account also explains why the universal acceptance of nativism argument is so widely accepted as relevant to the establishment of innateness claims. What the universal acceptance of nativism argument purports to show is that at least some psychological acquisition mechanisms cannot themselves be acquired by other psychological mechanisms. Unless this was so, our psychological theories would be either circular or lead to infinite regress. It is concluded, therefore, that at least some cognitive mechanisms must be innate. On the primitivist account, it is easy to explain the relevance of this argument to the establishment of innateness claims. According to primitivism,

29 See Cowie (1999, Part III) for a detailed discussion of this issue. 
any psychological mechanism that is not acquired by a psychological process or mechanism is innate. In which case, on the primitivist view, it follows immediately from the claim that there are some psychological mechanisms whose acquisition is not explained by a psychological process that some psychological mechanisms are innate.

\subsection{The Significance Constraint}

Let's turn now to the last of our constraints: the significance constraint. According to this desideratum, a satisfactory account of nativism in cognitive science should explain why nativism matters to cognitive scientists. Once more, primitivism can explain why this is so. Indeed, it directs out attention towards two important and closely related roles that innateness claims play within cognitive science. First, determining whether or not a cognitive structure is innate (i.e. psychologically primitive) plays a crucial role in psychology and cognitive science because it delimits the explanatory scope of psychological explanation. In other words, once we know that a given structure (e.g. universal grammar) is innate, we also know that our psychology should not—indeed, cannot—explain how it was acquired. And though it is unclear why this should matter much to anyone outside of psychology, it should be obvious that this is an important kind of information for anyone concerned with the construction of a comprehensive account of human psychology.

A second and closely related reason why, on the primitivist view, nativism matters to cognitive science is that discovering which structures are innate also furnishes us with the resources from which to construct our psychological theories. Psychology as a science-especially developmental psychology-presupposes the existence of structures whose acquisition is not explained by psychology. This is precisely the point of the argument for the universal acceptance of nativism. But if we know that a given structure is innate (i.e. psychologically primitive) and that it was acquired reasonably early in development, then we also have excellent reason to suppose that it is a structure that can be invoked by a psychological theory in order to explain the development of other psychological structures that are acquired later in development. In short: we can assume that it is a 'building block' that can be invoked by psychological theories of development. Once again, while this may not be of much interest to people outside of psychology and cognitive science, it is clearly of vital importance to anyone who wishes to develop a comprehensive account of human cognition. And since this is a central goal of cognitive science, it is clear why cognitive scientists should care about nativism.

\section{The Overgeneralization Problem}

I have argued that primitivism has the notable virtue of explaining the central features of innateness claims — and debate over nativism — as they figure in cog(C) Blackwell Publishers Ltd. 2002 
nitive science. Though this merits taking the account very seriously indeed, there is, nevertheless, a significant problem with the proposal. Specifically, there appear to be clear counter-examples-instances in which the account classifies cognitive structures as innate even though we would not be at all inclined to do so. In the present section I describe this overgeneralization problem in more detail and very briefly consider three potential solutions.

\subsection{The Problem}

It is easy to generate fictional instances in which the overgeneralization problem arises. Consider, for example, Fodor's Latin pill — a pill that, when ingested, induces knowledge of the grammar of Latin (Fodor, 1981). Possessing knowledge of Latin is a psychological state. By hypothesis, however, the causal cascade initiated by ingesting the pill does not have a psychological description, but works by reorganizing the underlying neurochemistry of the brain. So, the knowledge structure is psychologically primitive, hence, according to primitivism, innate, even though we would not be at all inclined to categorize the structure in this way.

If the only counter-examples to primitivism were of the fictitious (not to mention unrealistic!) 'Latin pill' variety, then perhaps there would be no serious grounds for concern. Clearly, there is something counterintuitive about classifying structures acquired in this bizarre fashion as innate, and this suggests that the primitivist account is unsatisfactory as a piece of ordinary language conceptual analysis. But, as mentioned earlier, ${ }^{30}$ we are not engaged in such an analysis. Instead we aim to explain the role of innateness - and debate over nativism - in the theories and explanatory practices of cognitive scientists. And, of course, such bizarre cases play no interesting role whatsoever within cognitive science.

Unfortunately, not all the putative counter-examples to primitivism are so easily ignored. Another, more realistic kind of example concerns environmental insults that result in psychopathological conditions. There are at least two kinds of such example:

1. One important class of cases involve diseases that have specific psychological effects but have them because of causal processes that do not appear to have any psychological description. So, for example, Ross River Fever, which is a new tropical disease in northern Australia carried by mosquitoes, is said to cause its victims to hallucinate buildings crashing down on the road in front of them. Nevertheless, there seems to be no way to describe this psychological effect as resulting from any psychological mechanism or process. Rather the disease has

30 See footnote 2 . 
a psychological effect via a mechanism that can only be described biologically. ${ }^{31}$

2. Another kind of case concerns environmental insults that cause brain lesions. The neuropsychological literature is replete with cases of this sort where cognitive effects result, even though there appears to be no psychological explanation of how they have these effects. ${ }^{32} \mathrm{~A}$ person might, for example, as a result of a fall or a car crash, suffer brain damage that eventuates in memory loss, problems performing basic arithmetic tasks or the presence of a red image in the visual field. In such cases, however, there appears to be no psychological explanation of how the environmental insult has its cognitive effect. Rather, the insult has its effect by damaging the neural mechanisms that subserve cognition.

\subsection{Three Potential Responses to the Overgeneralization Problem}

How should the primitivist respond to these cases? One option would be to argue that they are not instances in which cognitive structures are acquired. It might be, for example, that these are merely cases in which cognitive structures are destroyed (the brain lesion cases) or pre-existing cognitive structures are used in order to produce specific cognitive states-e.g. the illusion of buildings falling onto the road. But this strategy is unattractive. First, it places too much weight on the notion of cognitive structure, and since it is unclear how we ought to characterize this notion, one may well worry-with good reasonthat this manoeuver fails to address a crucial question, namely: Why aren't the above instances ones that involve the acquisition of new cognitive structure? Second, even if we were to assume that the above cases do not involve the acquisition of new cognitive structure, it is hard to see why there couldn't be closely analogous cases in which new cognitive structure is acquired. It has been suggested to me, for example, that a version of Obsessive-CompulsiveDisorder, known as PANDAS ('Post-Adolescent Neurological Disorder After Strep'), might involve the acquisition of new cognitive structure even though the explanation of how such structures are acquired is not a psychological one, but one that draws on the consequences of contracting Strep during adolescence. ${ }^{33}$ It is surely desirable that an account of innateness accommodates this sort of possibility.

Another approach to addressing the overgeneralization problem would be to add an extra condition to the primitivist proposal. But what should this con-

\footnotetext{
31 I'd like to thank Peter Godfrey-Smith for providing me with this example and for helpful discussions of the overgeneralization problem.

32 See Shallice (1988) for an excellent introduction to neuropsychology.

33 I would like to thank Dominic Murphy for suggesting this example.
} 
dition be? One prima facie plausible approach involves utilizing the notion of (mal) function. We might suggest, for instance, that a cognitive structure $\mathrm{S}$ is innate only if the state that results when $\mathrm{S}$ is acquired is not one that involves malfunction. Such a strategy deals with the examples outlined in section 5.1 since they are clearly examples which involve malfunction. But it also suffers from an important deficiency, namely: it precludes the possibility of malfunctioning innate structures, even though this seems to be a genuine possibility and one that is relevant to cognitive science. For example, Leslie's explanation of 'theory of mind' deficits in autistics, maintains that an innate, ToM module is malfunctioning (Leslie, 1994). But if a structure is innate only if its acquisition does not involve a state of malfunction, then contrary to appearances, this is impossible. This highlights the fact that, pace the present proposal, there may well be cognitive structures that are innate (hence, psychologically primitive) even though their possession involves being in a state of malfunction.

A final approach to addressing the overgeneralization problem, and the one that I favor, is to add a normalcy condition to the primitivist proposal. For instance, one might add the following necessary condition:

Normalcy Condition. A (token) cognitive structure S possessed by an organism $\mathrm{O}$ is innate only if $\mathrm{O}$ would acquire $\mathrm{S}$ (in the baseline sense) in the normal course of events.

No doubt, there is much that could be done in order to elaborate and clarify this suggestion. In particular, it would be useful to have an explicit account of what counts as a normal course of events. ${ }^{34}$ For present purposes, however, I leave such matters of detail to one side. Instead, the point I want to stress is that adding a normalcy condition seems like the right kind of strategy for addressing the overgeneralization problem. This is because, on a natural reading, it appears to exclude the examples outlined in section 6.1 from counting as innate. Prima facie, it is very plausible indeed to maintain that accidents which result in mind-altering brain lesions are not part of our normal development, and nor is contracting diseases that lead to the acquisition of novel cognitive structure. On the contrary, they seem to be clear instances of abnormal development. ${ }^{35}$ So, according to the normalcy condition they are not innate. Moreover, the normalcy condition also addresses these cases in an intuitively plausible manner. Precisely what seems so strange about viewing these pathological cases as instances in which innate structures are acquired is that they are cases of abnormal development-instances in which accidental environmental factors alter the standard course of development.

34 See Stich (1975) and Lloyd (1994) for useful, though incomplete, discussions of this issue.

35 We might add that the present proposal also deals with the Latin Pill cases. Popping such pills clearly isn't part of the normal course of events. 


\section{Some Implications of Primitivism}

I have suggested that we revise primitivism in order to address the overgeneralization problem by adding a normalcy condition to the primitivist condition outlined in section 3. I conclude by discussing three further implications of this revised primitivism for how we should think about nativism in cognitive science.

\subsection{Implications for Neurobiological Arguments Against the Existence of Innate Cognitive Structure}

One important consequence of the primitivist account of nativism is that it implies that a recent and highly influential argument from experimental neuroscience (Elman et al., 1996; Quartz and Sejnowski, 1994) is simply irrelevant to issues about the existence of innate cognitive structure. According to this neurobiological argument, 'evidence has been mounting against the notion of innate domain-specific microcircuitry as a viable account of cortical development' (Elman et al., 1996, p. 26). The evidence in question comes from a variety of recent cortical plasticity studies on vertebrate animals, where 'investigators have changed the nature of the input received by a specific area of cortex, either by transplanting plugs of fetal cortex from one area to another ... by radically altering the nature of the input by deforming the sensory surface ... or by redirecting inputs from their intended target to an unexpected area (e.g. redirecting visual inputs to auditory cortex)' (Elman et al., 1996, p. 26). According to advocates of the neurobiological argument, if we possess innate, domain-specific structures, then the cognitively salient properties of fetal cortical tissue-e.g. what the pieces of tissue represent or what functions they compute-would not be significantly altered by the above kinds of experimental manipulations. But this is not what occurs:

Surprisingly, under these aberrant conditions, the fetal cortex takes on neuroanatomical and physiological properties that are appropriate for the information received ... and quite different from the properties that would have emerged if the default inputs for that region had occurred (Elman et al., 1996, pp. 26-27). ${ }^{36}$

On the basis of this result, Elman et al. (1996) conclude that 'the cortex appears to be an organ of plasticity' - an organ whose representational properties are

36 So, for instance, in a series of experiments, Dennis O'Leary and his colleagues successfully transplanted pieces of fetal cortical tissue from one region of the newborn rodent cortex (e.g. the visual cortex) to another (e.g. the somatosensory region) (O'Leary and Stanfield, 1989). What they discovered is that the transplanted tissue takes on the structural and functional properties of its new location as opposed to maintaining the structure/function of its developmental origins and that these structural and functional properties are determined, in part, by the character of the sensory inputs that the transplanted tissue receives.

(C) Blackwell Publishers Ltd. 2002 
highly flexible in response to environmental change (p. 315). And from this they infer that 'right now the case for innate representations does not look very good' (pp. 26-27). Similarly, Quartz and Sejnowski conclude on the basis of much the same evidence that 'from a neurobiological perspective, the nativist position and the related modularity thesis are highly implausible' (Quartz and Sejnowski, 1994, p. 726).

If sound, the neurobiological argument would clearly pose a serious challenge to the nativist tradition in cognitive science. It would imply, for example, that there are no innate domain-specific modules or innately specified representations. But I maintain that the argument is not sound. ${ }^{37}$ Indeed, if the revised primitivist account of innateness is correct, then it is far from clear that the sorts of evidence invoked by advocates of the neurobiological argument is even relevant to debate over nativism in cognitive science. In order for these studies to be relevant, they would need to bear on either of the following issues: (a) Are domain-specific cognitive structures psychologically primitive? (b) Do organisms come to possess these domain-specific cognitive structures in the normal course of development? But the evidence appears to bear on neither of these issues.

First, the evidence clearly does not bear on the issue of whether or nor domain-specific cognitive structures are psychologically primitive. And this is simply because the kinds of evidence invoked by the neurobiological argument are silent on the matter of whether or not the mechanisms (or processes) responsible for the acquisition of domain-specific cognitive structures are psychological ones. What the neurobiological argument does show is that experimental manipulations can alter the domain-specific properties of pieces of cortical tissue. But this clearly does not tell us whether or not psychological mechanisms (or processes) are responsible for acquiring domain-specific cognitive structures. So, the neurobiological argument won't settle the question of whether or not these domain-specific structures are psychologically primitive.

Similarly, the neurobiological argument does not appear to bear on the question of whether or not domain-specific cognitive structures are the product of normal development. The reason becomes clear when we ask the question 'Does a course of events in which a neurobiologist performs invasive experiments on a developing organism count as a normal course of events for that (kind of) organism?' Does, for example, a course of events in which a neuroscientist opens up a human neonate's skull and moves pieces of cortical tissue around (or rewires the afferent inputs to pieces of cortical tissue) count as a normal one? The answer is clearly 'No'. On any plausible view as what counts as a normal course of development, such circumstances are surely abnormal. The environmental conditions under which humans have typically developed do not involve such invasive surgical procedures. Furthermore, such

37 See Samuels (1998) for a more extended critique of the neurobiological argument. 
procedures alter species-typical patterns of development. According to revised primitivism, then, using the results of such invasive experiments in order to argue against the existence of innate, domain-specific cognitive structure is rather like arguing against the claim that having only two hands and ten fingers is innate on the grounds that I would have developed no hands at all had I been exposed to thalidomide in utero. A course of events in which I am subjected to levels of thalidomide sufficiently large to inhibit the growth of hands is not a normal one and nor is a course of events in where my brain is rewired by a neurobiologist as part of a cortical plasticity study. Yet if such courses of events don't count as normal ones, then experimental data taken from invasive studies clearly won't resolve the debate over whether or not a given characteristic is a product of the normal course of events. After all, such experiments only tell us what happens in circumstances which are, by hypothesis, abnormal.

\subsection{The Devolution of Debates Over Nativism Into Debates Over the Nature of Scientific Psychological Explanation}

A second important implication of revised primitivism is that, if correct, we should expect that debate over nativism will frequently devolve into a debate over the nature of scientific psychological explanation-especially about the kinds of psychological structures, mechanisms and processes that a scientific psychology ought to posit. In other words, debate over nativism should frequently devolve into a dispute over what I earlier called the Question of Form. The reason is that different kinds of psychological theories may well have different resources with which to explain the acquisition of psychological structure and, this in turn, will affect our answer to the question of whether or not a given structure is psychologically primitive.

As far as I can tell, the above primitivist prediction is confirmed. As a matter of fact, precisely what we find when we look at debates over nativism in cognitive science is that they frequently devolve into disputes over the nature of scientific psychological explanation. So, for example, the debate between early cognitivists, such as Chomsky, and behaviorists, such as Skinner, frequently turned into a debate over what kinds of theory ought to be constructed in order to explain behavior in general and linguistic behavior in particular. Very roughly, Skinner maintained that the resources of behaviorist psychology - a restricted range of associationist mechanisms and exposure to a regime of conditioning-were sufficient to explain behavior. By contrast, Chomsky and others adopted the cognitivist view that we need to posit internal, semantically evaluable psychological structures (Cowie, 1999). Nor is this an isolated example. More recently, debates between nativists and their opponents have frequently devolved into debates over the relative merits of classical and connectionist theories of cognition. Thus, for example, a number of connectionist theorists have rejected standard arguments for the innateness of linguistic knowledge on the grounds that they presuppose an implausible 
account of psychological processes as algorithmic processes defined over discrete symbolic structures (Elman et al., 1996). But this, of course, is tantamount to rejecting the classical account of cognitive processes. Thus connectionists appear to be trying to undermine the case for nativism by rejecting the view of scientific psychological explanation on which it is predicated.

What is the take-home message of all this? What I think these sorts of examples show is that the connection between debate about nativism and debate over the nature of scientific psychological explanation is far more intimate than one might have initially thought. Indeed, I suspect that in many cases, the two sorts of issue must be addressed simultaneously. Finally, the fact that revised primitivism predicts this intimate connection is surely a virtue of the proposal.

\subsection{On the (Near) Intractability of Debate Over Nativism}

A final consequence of the revised primitivist account is that it helps explain why debates over nativism are so hard to resolve. The problem is that in order to resolve such debates we need to address issues about what the form of scientific psychological explanations ought to be-what kinds of processes and structures a mature scientific psychology ought to posit. This is just the point I make in 6.2. But in order to resolve this debate, we also need to have some reasonably clear idea of what basic cognitive structures there are-what basic elements can be invoked in the construction of psychological theories but whose acquisition, psychology need not explain. And this amounts to saying that we need to know what (kinds of) psychologically primitive structures there are-what structures are innate. Now, I don't want to suggest that this means there's some kind of vicious explanatory circularity at the heart of cognitive science. After all, there are plenty of instances in science where answers to different questions undergo mutual adjustment in the light of further discoveries such that they cohere. But it does mean that two of the hardest questions in cognitive science- 'What innate structures are there?' and 'What kinds of theories of cognition ought we to develop?' need to be addressed in tandem. No doubt this is not good news for cognitive scientists who have tended to characterize the two issues as if they were more-or-less independent. The need to address them together may well make addressing either problem all the more difficult.

Department of Philosophy

King's College London

\section{References}

Allen, C., Bekoff, M. and Lauder, G. (eds.) 1998: Nature's Purpose: Analyses of Function and Design in Biology. Cambridge MA: MIT Press. 
Ariew, A. 1996: Innateness and canalization. Philosophy of Science, 63 (Proceedings), pp. S19-S27.

Ariew, A. 1999: Innateness is canalization: In defense of a developmental account of innateness. In V. Hardcastle (ed.) Where Biology Meets Psychology. Cambridge, MA: MIT Press.

Block, N. (ed.) 1981: Readings in the philosophy of psychology. Volume 2. London: Methuen.

Bruner, J.S., Goodnow, J.J. and Austin, G.A. 1956: A Study of Thinking. New York: Wiley.

Carey, S. and Spelke, E. 1994: Domain-specific knowledge and conceptual change. In L. Hirschfeld and S. Gelman (eds.) Mapping the Mind. Cambridge: Cambridge University Press.

Chomsky, N. 1980: Rules and Representations. New York: Columbia University Press.

Chomsky, N. 1988: Language and the Problems of Knowledge. Cambridge MA: MIT Press.

Chomsky, N. 1991: Linguistics, a personal view. In Kasher A. (ed.) The Chomskyan Turn. Oxford: Blackwell.

Cottingham, J, Stoothoff, R. and Murdoch, D. (trans.) 1988: Descartes: Selected Philosophical Writings. Cambridge: Cambridge University Press.

Cowie, F. 1999: What's Within? Nativism Reconsidered. Oxford: Oxford University Press.

Elman, J., Bates, E., Johnson, M., Karmillof-Smith, A., Parisi, D. and Plunkett, K. 1996: Rethinking Innateness: A Connectionist Perspective on Development. Cambridge, MA: MIT Press.

Fodor, J. 1981: The present status of the innateness controversy. In Representations. Cambridge, MA: MIT Press.

Fodor, J. 1983: Modularity of Mind. Cambridge, MA: MIT Press.

Fodor, J. 1987: Psychosemantics. Cambridge MA: MIT Press.

Fodor, J. 1998a: Concepts: Where Cognitive Science Went Wrong. Oxford: Oxford University Press.

Fodor, J. 1998b: In Critical Condition. Cambridge, MA: MIT Press.

Griffiths, P. 1997: What Emotions Really Are. Chicago: University of Chicago Press.

Griffiths, P. and Gray, R. 1992: Developmental systems and evolutionary explanations. Journal of Philosophy, 91, 277-304.

Griffiths, P. and Sterelny, K. 1999: Sex and Death: An Introduction to Philosophy of Biology. University of Chicago Press;

Hardcastle, V. (ed.) 1999: Where Biology Meets Psychology. Cambridge, MA: MIT Press.

Hirschfeld, L. and Gelman, S. (eds.) 1994: Mapping the Mind. Cambridge: Cambridge University Press.

Karmiloff-Smith, A. 1992: Beyond Modularity: A Developmental Perspective on Cognitive Science. Cambridge, MA: MIT Press.

Kitcher, P. 1996: The Lives To Come. New York: Simon \& Schuster.

Laurence, S. and Margolis, E. 1999: Concepts and cognitive science. In E. Margolis and S. Laurence (eds.) Concepts: Core Readings. Cambridge, MA: MIT Press.

(C) Blackwell Publishers Ltd. 2002 
Leslie, A. 1994: ToMM, ToBY, and agency: Core architecture and domain specificity. In L. Hirschfeld and S. Gelman (eds.) Mapping the Mind. Cambridge: Cambridge University Press.

Lloyd, E. 1994: Normality and variation: The human genome project and the ideal human type. In C. F. Cranor (ed.) Are Genes Us? The Social Consequences of the New Genetics. New Jersey: Rutgers University Press.

Neander, K. 1988: What does natural selection explain: Correction to Sober. Philosophy of Science, 55, 422-426.

O’Leary, D.D. and Stanfield, B.B. 1989: Occipital cortical neurons with transient pyramidal tract axons extend and maintain colaterals to subcortical but not intracortical targets. Journal of Neuroscience, 9(7), 2230-2246.

Oyama, S. 1985: The Ontogeny of Information. Cambridge: CUP.

Piattelli-Palmarini, M. 1979: Language and Learning: The Debate Between Jean Piaget and Noam Chomsky. London: Routledge and Kegan Paul.

Pinker, S. 1994: The Language Instinct. New York: William Morrow and Co.

Pinker, S. 1997: How The Mind Works. New York: Norton.

Quartz, S. and Sejnowski, T. 1994: Beyond modularity: Neural evidence for constructivist principles in development. Behavioral and Brain Sciences, 17, 725-726.

Quine, W.V.O. 1969: Linguistics and philosophy. In S. Hook (ed.) Language and Philosophy: A Symposium. NYU Press.

Samuels, R. 1998: What brains won't tell us about the mind: A critique of the neurobiological argument against representational nativism. Mind \& Language, 13, 4, 548-570.

Scholl, B.J. and Leslie, A.M. 1999: The innate capacity to acquire a 'theory of mind': Synchronic or diachronic modularity? Mind \& Language, 14, 131-153.

Shallice, T. 1988: From Neuropsychology to Mental Structure. Cambridge, Cambridge University Press.

Sober, E. 1995: Natural selection and distinctive explanation: A reply to Neander. British Journal for the Philosophy of Science, 46(3), 384-397.

Sober, E. 1999: Innate knowledge. In The Routledge Encyclopedia of Philosophy, Vol. 4, 794-797. Routledge.

Stich, S. (ed.) 1975: Innate Ideas. University of California Press.

Wimsatt, W. 1999: Generativity, entrenchment, evolution, and innateness: philosophy, evolutionary biology, and conceptual foundations of science. In V. Hardcastle (ed.), Where Biology Meets Psychology . Cambridge, MA: MIT Press.

Wynn, K. 1992: Addition and subtraction by human infants. Nature, 358, 749-750. 